\title{
Research on Education of Students' Morality and Emotion in Higher Vocational Colleges
}

\author{
Shuo Huang, Mingliang Huang and Sisi Du \\ College of Music ,Jiangxi University of Technology
}

Keywords: Higher vocational college students; Morality and emotion; Rducation on morality and emotion.

\begin{abstract}
In the Several Opinions on Improving the Quality of Higher Vocational Education Comprehensively, Ministry of Education has clearly pointed out that education in higher vocational colleges should give priority to moral education by putting students in the first place, that is to say, education on students as well as students' morality should be served as a fundamental task, which requires vocational colleges to give even more attention to moral education and put it in a prior position. The basic task of moral education is to affect students' personality to form morality, that is, the moral character, which includes moral cognition, moral emotion, moral will, moral belief and moral behaviors. As far as the basic psychology during the formation of individual moral character is concerned, it is a process from knowledge to behaviors. As for current moral education in higher vocational colleges, it extends more emphasis on cognition while less attention to emotions, leading to a less ideal effect of moral education. In order to promote the efficiency of moral education, more emphasis should be laid on moral emotional education. That is, while conducting education on moral cognition, we should also pay more attention to the cultivation of moral emotion.
\end{abstract}

\section{Introduction}

As for current higher vocational college students, most of them were last admitted to vocational colleges because they failed to enter good universities. They seem to be lost and helpless to study in a vocational college, so they may look negative to some extent. Under this circumstance, vocational colleges should give more concerns to students' moral education as well as humanistic cares. However, at present, there is a universal lack of moral education and humanistic care to students in vocational colleges. They are only concerned about students' practice and study of professional skills with little concern about moral and humanistic education. It seems that vocational colleges are inclined to be made a professional training base. It's neither suitable for students' individual all-round development, nor conform to national and people's long-term interests. Students graduated from vocational colleges should possess perfect skills as well as sound thoughts, emotions and personalities. Their future should possess sound personality, strong sense of responsibility as well as enough wisdom and skills. Therefore, equal attention should be paid to moral and humanistic education along with practical training. On the other hand, there is a universally low efficiency of moral education in vocational colleges. While reflecting on the reasons for low efficiency, the author thinks that less attention has been paid to cultivating moral emotion and exercising moral will, though much emphasis has been laid on moral rules during moral education and practice. Actually, as for most students, they know how to conduct moral behaviors, but it is difficult for them to abide 
by moral rules with disunity of knowing and action, which is caused by imperfect cultivation on moral emotion and moral will. In fact, during the education, we can also deeply feel that pure implantation of moral theories and moral rules without cultivation on students' moral emotion will lead to empty preaching without thrilling vitality and appeal. Moral cognition is the precondition of moral behavior, but it does not mean moral cognition can lead to corresponding moral behavior; while only a firm moral will and belief is formed by the integration of moral cognition and moral emotion that moral cognition can be turned into corresponding moral behavior with unity of knowing and action. Thus, it is a subject needing to be solved urgently during moral practice in vocational colleges to cultivate and educate students' moral emotion.

The so-called moral emotion is a special emotion that humans have during social life. It is not only an major content for humans' subjective morality, but it is also an important factor for humans' psychological morality. Moral practice is caused by deep emotional experience besides rational single function. The moral emotion has an interaction with moral cognition, throughout the whole process of humans' moral activities.

As for current moral education and practice in higher vocational colleges, although we all agree that both theories and emotions should be valued, educators always put more emphasis on theories but less emphasis on moral emotions. The phenomenon mainly manifests in the following two aspects.

On one hand, narration and popularization of moral knowledge have been seen as main content of moral education; while cultivation on students' moral emotion has been considered a subordinate position. It is simply considered that students can be affected with sufficient theories and reasons.

On the other hand, there is more attention to the effect of moral cognition on moral emotion, but the contrary effect has not been much too concerned. As a result, the current moral education is obviously characterized with preaching, which attaches greater importance to implantation and teaching of theoretical and rational knowledge but less importance to students' experience and internalization.

For sure, people's moral self-conscious behaviors are connected to their knowledge about right and wrong. However, generally, the existing moral knowledge and intelligence level can only provide possibilities for their moral activities, but they can't decide which moral activities should be conducted. It is emotion that stimulates people's voluntary moral behaviors, that is, people's emotional experience on moral education as well as moral demand generated during this process. Although students may obtain certain moral cognition from educators, they may not produce the same moral experience and moral need as the educators have. According to previous moral education and practice, we conclude that if students only have rational knowledge without emotional experience or need, they may grow into moral hypocrites who can only brag instead of truly moral man. Therefore, moral education on vocational college students should not only value the improvement of moral knowledge, but it should also strengthen their identification of moral emotion so as to arouse their emotional need, and thus students can be cultivated into real moral humans with morality all the time.

This paper aims to find out vocational college students' moral and emotional characteristics as well as problems existing in their moral education by analyzing and studying the status quo of higher vocational college students' moral emotion as well as current education on morality and emotion in vocational colleges so as to explore the reasons for these problems as well as the important significance of moral education on vocational college students' growth combined with the effect and 
function of moral emotion during the formation of individual sound morality. Education on morality and emotion has been studied by combing theories with practice so as to find out research countermeasures and to achieve sound moral effect.

\section{The meaning of education on vocational college students' morality and emotion}

The meaning as well as important significance of moral education has changed a lot with the development of market economic system and social values. Compared to economic development, cultural construction, especially the construction of moral culture has always been lacked behind due to the backward cultural development. The disunity of moral construction and economic development has resulted in exaggeration of moral declination and social disharmony. Many reasons have contributed to these problems, within which one of the most important aspects is the lack of people's moral emotion. It has been an urgent need for constructing a harmonious society to solve the contradictions and eliminate inharmonious factors so as to promote people's moral emotions. Vocational colleges, as education institutes to cultivate social talents, they have a responsibility of cultivating students' sound morality and emotion. It is of great importance to cultivate lofty and strong moral emotions, which is beneficial to build a harmonious interpersonal relation, create sound moral atmosphere and form sound individual moral character. In addition, under today's circumstance of building a harmonious society, which is proposed by Chinese Communist Party Central Committee, vocational colleges should pay even more attention to students' moral education so as to promote vocational college students' morality and form sound moral character. Before enforcing effective moral and emotional education on vocational college students, we should first understand and clarify the meaning of moral emotion, and realize the great importance of implementing moral education on vocational college students.

The meaning of moral and emotional education. First, moral emotion is part of moral consciousness, which means people's internal experience and emotional attitude such as admiration, interest or hate for moral relations and moral actions occurred in realistic life based on certain moral cognition. Similar to rational feeling and aesthetic feeling, moral feeling belongs to human's advanced feelings. Moral feeling is a basic section for the formation of corresponding moral character, which constitutes major factors of morality together with moral cognition, moral will, moral belief and moral actions.

The second is moral and emotional education. Moral and emotional education means education on related morality and emotion, which aims to cultivate students' moral feelings by experiencing moral situation so as to enrich their emotional experience; and meanwhile their moral emotion can be greatly promoted so as to promote their moral level. Thus, the efficiency of moral education can be improved through such kind of educational way.

The meaning of education on vocational college students' morality and emotion. According to analysis on moral and emotional education above, the author thinks that moral and emotional education on college students should be implemented based on students' growth and development rules and features so as to cultivate their moral emotion, emotional morality. It is a moral educational way, which emphasizes on enriching vocational college students' emotional experience, and based on this precondition, vocational college students' cognition of existing moral rules and principles can be internalized so as to produce moral emotional need and form moral behaviors. In this way, vocational college students' moral personality and accomplishment can be promoted. 
The important significance of implementing moral and emotional education on higher vocational college students. Moral emotion is closely related to social development, and the development of individual moral emotion is inevitably affected by social development. Moral emotion of contemporary university students is unique under today's background of close global economy, highly developed science and technology as well as increasingly frequent cultural exchanges. In addition, most vocational college students are under a age of 17 to 20, during which individual emotion and sentiment are fully developed, and meanwhile social high-level emotions such as moral emotion are developed fast and positively. Vocational college students under this period are inclined to absorb more external information subjectively with the fiercest ideological contradictions, and their moral character is developed and formed during the conflict. However, moral development of vocational college students has been greatly impacted due to the utilitarian effect brought by fast development of modern social economy as well as virtual world brought by network age, etc. While enjoying the abundant material life and obtaining knowledge conveniently due to the opening up and reform and network age, students have also been impacted and challenged by various western decadent ideas. Because of different moral values, students have different opinions on career, fortune, family, country and happiness. Most of them began to possess moral ideas like money worship, hedonism, pessimism and personal happiness and so on, which have a negative effect on guiding their moral emotions. Thus, educators should attach even more importance to vocational college students' emotions with attention to the situation as well as development rules of their moral emotion; meanwhile, educators should lead vocational college students' moral emotion to development positively by implementing moral and emotional education positively and effectively. Moral and emotional education on vocational college students is of great significance for improving the situation of college students' moral emotion, ideological and political education in vocational colleges as well as vocational college students' cultivation and growth.

First, moral and emotional education in higher vocational colleges is of great importance for improving the situation college students' moral emotion in vocational colleges; second, it is of significant importance for ideological and political education to implement moral and emotional education among vocational college students; third, moral and emotional education in vocational colleges is important for students' growth and cultivation.

Only if young students learn how to behave themselves, they can learn to make preparations for their study and career so as to achieve success. Therefore, in this sense, it is more important to cultivate young students' knowledge about behaving themselves than study. Thus, moral emotion is the base for their future development during their growth, while moral and emotional education is of great importance for their growth and cultivation.

\section{Investigation and analysis on the status quo of moral and emotional education among vocational college students}

At present, during the study and practice of moral education in vocational colleges, there hasn't aroused enough concerns both theoretically and practically. Compared to the whole university and college students group, students from higher vocational colleges have their own particular features. They have different and specific emotional development, and thus specific moral and emotional education should be implemented on them so as to receive expected educational effect. Then, at present, how is the moral and emotional education among vocational college students? Do they have any insufficiency? All of these problems require us to conduct study and investigation carefully with 
analysis on the reasons on the whole. In this way, moral and emotional education on vocational college students can be improved specifically so as to promote the practicality of moral education in vocational colleges.

Investigation on moral and emotional education among vocational college students. According to the previous researches, although many scholars have studied the ideological and moral education among college students, there is less study on moral and emotional education, let alone investigation on moral and emotional education of vocational college students specifically. In order to acquire a deep and comprehensive understanding of moral and emotional education among vocational college students, the author has carried out some investigations in the school he works in on students in terms of the necessity, present situation as well as effect. The investigation results have been showed as below.

1、 The necessity of implementing moral and emotional education has been identified by vocational college students universally.

2、The overall implementation of moral and emotional education among vocational college students is not ideal.

3、 Vocational college students' need for moral and emotional experience has not been satisfied.

4、 Implementing education based on emotion has not achieved ideal effect.

5、 The atmosphere created for moral and emotional education in vocational colleges needs to be improved.

6、 The effect of teachers and administrative staff's moral and emotional condition on students.

The reasons for problems existing in the moral and emotional education for vocational college students. According to the author, the main reasons can be analyzed from the following three aspects. First, moral and emotional education in vocational colleges should be considered; besides, effects from social environment as well as students themselves should also be considered.

First, there are some problems existing during moral and emotional education in vocational colleges. (1) Vocational colleges have insufficient knowledge about moral education; (2) the practice of moral education in vocational colleges is deficient and biased; (3) the content design for moral education in vocational colleges is irrational; (4) the implementation of moral education in vocational colleges is biased; (5) the establishment of personnel for moral education in vocational colleges is unsuccessful.

Second, campus culture has been impacted by social environment. (1) Moral feelings of vocational college students have been affected by the dual effect of market economy; (2) moral and emotional education for vocational college students has been impacted by the development of mass culture.

Third, vocational college students' self-education on morality needs to be further strengthened. First of all, self-education for morality is necessary for the internalization of moral cognition; besides, people's morality has been constantly perfected during their growth.

The content of moral and emotional education among vocational college students

During university and college stage, vocational college students' morality and emotion has become mature. Compared to middle-school stage, students at this stage present even deeper and higher demand for moral and emotional education. However, at present, the development of morality and emotion for vocational college students has been deficient periodically. Some moral feelings and characters which should be established in primary and middle schools have not been finished. Such kind of periodical deficiency has made moral and emotional education in vocational colleges even 
more difficult and complicated at a primary level. Thus, the content design of moral and emotional education should fully take these conditions and features into consideration. According to the goal of moral and emotional education as well as status and features of moral and emotional development among vocational college students, the following several main contents should be valued during moral and emotional education for vocational college students.

Firstly, vocational college students' sense of responsibility shall be cultivated since it is a major part of moral and emotional education. A sense of responsibility is a positive and beneficial spirit that is carried forward by human subjectively to treat himself, nature and society including nation, collective, family and others. It is main content of ideological and moral quality, which lies in a core position of moral quality. That is, there is no so-called morality without a sense of responsibility.

Secondly, vocational college students' dedicated moral feelings to work should be cultivated. The Ministry of Education has pointed out clearly in the Several Opinions on Improving the Quality of Education and Teaching in Vocational Colleges Comprehensively that vocational moral education on students in vocational colleges should be highly valued according to students' unique features so as to cultivate technical talents who have high qualities, such as honesty, dedication and sense of responsibility. Therefore, vocational colleges should enhance vocational moral education.

Thirdly, vocational college students should be cultivated with a thankful heart. Grateful education is an important part of moral and emotional education for current vocational college students.

Fourthly, vocational college students should be cultivated with a sense of honor which is indispensable during the education of morality. Sense of honor is self consciousness and psychological feeling formed during the judgment of self behaviors based on social rules and standards on good and evil.

Means of implementing moral and emotional education for vocational college students

Correct idea should be first established for moral and emotional education in vocational colleges.

As for vocational colleges, they should create deep emotional atmosphere for educational management, educational activities, society establishment, campus culture and campus environment so as to give play to the field effect of overall college. In this way, college students' moral demand can be enlightened, and thus their lofty moral feelings can be cultivated and promoted. The following ideas should be established if vocational colleges want to ensure a good moral and emotional education.

First, the concept of imparting knowledge and educating people should be firmly established.

Second, the concept of combing knowledge education with morality education should be possessed by school.

Third, vocational colleges should have ideas and feelings of caring students sincerely.

Fourth, administrative staff in the vocational colleges should establish "people-oriented" idea and advocate humanization from administrative concept, administrative system and administrative style, caring for students with a sincere heart so that students can feel warm affections everywhere regardless of computer room or dormitory, library or canteen. Under this circumstance, students' moral emotions can be affected substantially.

According to cultivation goals, social practical activities for college students should positively guide them to contact society, understand society and serve society so that students can receive education during the process, leading to a group of students with comprehensive qualities. By taking part in social activities, students can enrich their experience, and on this basis, their moral emotions can be developed on moral cognition. Thus, they can further feel moral standards, stimulating and 
deepening wide moral need. Social practical activities are vivid and lively, which can solve the boring and rigid explanation in class so as to form deep moral emotion more easily. During the participation of social activities, college students can experience emotions which are deeper than class education, and thus their sound moral emotions such as sense of responsibility, sense of obligation, sense of mission as well as sense of collectivism can be formed. Therefore, students should be provided with more chances with active implementation of military training, part-time work, internship, visit, social investigation, social service and scientific service and so on. Meanwhile, every student should be ensured a chance so that their overall moral emotions can be promoted.

Strengthen team construction of moral education

First, moral theories of moral team as well as the level of individual morality should be strengthened and improved.

Second, a group of moral experts should be cultivated in each school to work on moral education from the leadership.

Third, college students should be cultivated with rich moral emotion, and educators should possess rich emotional morality first.

Fifth, quality construction of instructor team in vocational colleges should be strengthened.

The effect of moral education as a carrier should be fully performed.

On one hand, moral and emotional education can be carried out through class education. First, the effect of ideological and political class should be brought into play; second, vocational moral emotions should be permeated in professional classes.

Moral and emotional education for vocational college students can be implemented with the full use of second classroom. First, beautiful campus environment can be built to promote morality education; second, elegant campus cultural atmosphere can be established; third, vocational college students' moral and emotional education can be strengthened by campus network construction.

\section{Vocational college students' self education can be enhanced.}

Sukhomlinskii once said self education is the commanding height of education. Self education means educatees produce positive attitude based on self consciousness and self experience according to educational goals and requirements ideologically and politically. They can accept advanced ideas and correct behaviors subjectively so as to forming sound ideological morality and behavioral means.

\section{Conclusions}

Vocational colleges are educational institutes aiming to cultivate social advanced technicians. They undertake important mission to cultivate modern talents with comprehensive development. Implementation of moral and emotional education on vocational college students is related to improving students' morality, perfecting the formation of their characters and promoting overall quality, which is implementation and enforcement of scientific development perspective by putting people in the first place as well as objective requirements for vocational college students' comprehensive development. Therefore, moral and emotional education on vocational college students is the main task of vocational colleges, which is of great importance for vocational college students' healthy development and social harmonious development. 


\section{References}

[1] Lu Jiamei, Yuanjun, Wang Junshan, Chenning. Study on Teenagers' Moral and Emotional Situation [J]. Education and Study, 2010(12):83-89

[2] Yang Yehua. Several Theories on Deepening Ideological and Political Education[J]. Marxism Research 2010(6):130-137

[2] Wu Qidong. Reflections on Strengthening Moral Education in Vocational Colleges [J]. Contemporary Education Forum, 2008(10):28-29

[3] Liu Biwan, Establishment of New Mode for Moral Education in Vocational Colleges[J]. Journal, 2009(1):40

[4] Feng Ligang, Yanru. Research on Self Moral Education Among University and College Students. [J]. Ideological and Political Education, 2009(6):102-104

[5] Zhang Jianrong. Difficulties and Reflection on Moral Education for University and College Students Under Market Economy.[J]. Research on Ideology and Education. 2011(1):64-67

[6] Zhang Hongxia. College Students' Self Education in Ideological and Political Education Under New Trend, 2010(11):64-66

[7] Li Guangyan, Cheng Rubing. Research on Enhancing Moral and Emotional Education by Ideological and Political Teaching. [J].Journal of Changchun Normal College (Humanity and Social Science), 2008(6):158-161

[8] Huang Jiahui, Liuli. Self Education on College Students' Morality Under Social Transition Stage [J]. Journal of Dalian Educational College, 2009(4):64-66

[9] Zhang Junchao. Discussion on the Effective Relations Between Moral Emotion Cultivation and Ideological Political Education, 2005(10):48-49

[10] Tian Xuefei, Zheng Jinchao. Analysis on Reshaping Morality Under Market Economy [J]. Journal from Shenyang Architecture University (Social Science), 2011(1):81-84 